Penultimate Draft

[Please cite published version Synthese (2017): DOI 10.1007/s11229-017-1329-8]

\title{
Is Imagination Too Liberal for Modal Epistemology? ${ }^{1}$
}

\begin{abstract}
Appealing to imagination for modal justification is very common. But not everyone thinks that all imaginings provide modal justification. Recently, Dominic Gregory (2010) and Peter Kung (2010) have independently argued that, whereas imaginings with sensory imageries can justify modal beliefs, those without sensory imageries don't because of such imaginings' extreme liberty. In this essay, I defend the general modal epistemological relevance of imagining. I argue, first, that when the objections that target the liberal nature of non-sensory imaginings are adequately developed, those objections also threaten the sensory imaginings. So, if we think that non-sensory imaginings are too liberal for modal justification, we should say the same about sensory imaginings. I'll finish my defense by showing that, when it comes to deciding between saying that all imaginings are prima facie justificatory and saying that no imaginings are justificatory, there is an independent reason for accepting the former.
\end{abstract}

\section{Justifying Modal Beliefs}

The goal of this essay is to defend the following Yablo-style modal epistemological policy against a particular kind of skeptical objection: For any statement $\mathrm{S}$, if $\mathrm{z}$ can conceive that $\mathrm{S}$, then $\mathrm{z}$ is prima facie justified in believing that $\mathrm{S}$ is possible. I'll call this principle Imaginative

${ }^{1}$ I would like to thank Ross Cameron, Brie Gertler, and Harold Langsam for commenting on multiple early drafts of this paper and for their patience with my stubbornness in philosophical conversations. My gratitude also goes to Matt Duncan, Trenton Merricks, Peter Tan, and the audience in the departmental retreat of the Corcoran Department of Philosophy, University of Virginia for their valuable feedback. I must also thank Nick Rimell and Jim Darcy, who kindly offered to help me with the linguistic aspect of the paper. Finally, I am grateful to the anonymous reviewers of Synthese for their suggestions that helped make this a much better paper. 
Conservatism. Following those who defend a similar view, ${ }^{2}$ I take conceiving and imagining to be the same attitude; 'imagining' and 'conceiving' will be used inter-changeably. ${ }^{3}$

In the recent literature, two kinds of moderate skepticism have been raised against the general principle of Imaginative Conservatism. They are moderate in the sense that, instead of banishing all conceivings from modal epistemology, they argue that some but not all conceivings provide modal justification. And these moderate skeptics differ in their ways of distinguishing the 'good' from the 'bad' conceivings.

The first kind of moderate skeptic distinguishes the good conceivings from the bad ones based on the subject matter of those conceivings. It says that only conceivings about mundane facts can justify beliefs about possibilities; conceivings about facts distant from our everyday life cannot. I call this Type-1 moderate skepticism (van Inwagen 1997; Hawke 2011).

The second kind separates the good ones from the bad ones, roughly speaking, based not on the subject matter of the conceivings but on the manner in which the conceiving is done. Very roughly put, they distinguish sensory conceivings from the non-sensory ones, and argue that the non-sensory conceivings don't provide even prima facie justification for claims about possibilities. I call this Type-2 moderate skepticism (Gregory 2010; Kung 2010).

Arguments for Type-1 moderate skepticism offered by van Inwagen and Hawke have been effectively addressed by Geirsson (2005) and Hartl (2016). So I won't try to reinvent the wheel here. Instead, I'll focus on defending the general epistemic relevance of conceivings against arguments for Type-2 moderate skepticism.

Type-2 skepticism can come in slightly different forms. But one feature unites them: they all find conceivings that are not based on the sensory too liberal to have any justificatory value. There hasn't been a focused response to the Type-2 skeptical worry yet. In this essay, I will offer one. My main goal is not to prove Imaginative Conservatism, but to argue that arguments against it from the Type-2 skeptics are not effective. I'll thereby show that there is no good reason to think that our imagination, sensory or not, is too liberal for modal epistemology.

\footnotetext{
2 This kind of conceivability-based modal epistemology is defended by Yablo in 'Is Conceivability a Guide to Possibility?' (1993) and is further developed by Geirsson (2005). Williamson (2007) is difficult to classify. Although he argues that we have access to modal truths only via learning about counterfactuals, according to his view, it is via imaginings that we learn about counterfactual truths. So, there is an indirect sense in which Williamson's view is also conceivability-based. It is worth noting that Imaginative Conservatism is a very weak claim. It does not rule out other sources of modal justification. Imagining is just a sufficient condition for prima facie modal justification, not a necessary condition. So, for example, Roca-Royes's (2011) objection against conceivability-based modal epistemology does not work against Imaginative Conservatism.

${ }^{3}$ Note that, although I say Imaginative Conservatism is a Yablo-style principle, it is not committed to every detail of Yablo's particular modal epistemology. For example, Yablo draws the distinction between objectual and propositional imaginings. And he thinks that the latter piggybacks on the former in providing modal justification. I remain deliberately non-committal when I say that conceiving and imagining are attitudes, leaving open whether they are attitudes to objects or to propositions. The subsequent discussion does not hinge on this distinction.
} 
Type-2 moderate skepticism is defended in slightly different ways by Gregory (2010) and Kung (2010). ${ }^{4}$ By contrasting their efforts, an assumption indispensable to their skeptical arguments will be brought to light. I'll argue that this assumption makes the moderate position sought by the Type-2 moderate skeptics highly unstable. I'll then complete my defense by casting doubt on the plausibility of embracing a more radical skepticism that denies the modal epistemological value of not just the non-sensory imaginings, but all imaginings.

\section{Gregory's Argument}

Suppose that I imagine Teddy eating a blue tomato by visualization. Such an imagining involves sensory qualities, e.g., the imagined visual experience of blue. But the imagining involves not just those sensory features but also a conceptual interpretation of the imagery, e.g., a portion of the sensory image is labeled as Teddy. Such a conceptual interpretation is called an assignment. $^{5}$

An imagining that consists of both imageries and assignments is an imagistic imagining. There are non-imagistic imaginings, too. I can imagine that water molecules are composed of four hydrogen atoms and two oxygen atoms. I can also imagine that space has five instead of three dimensions. Such imaginings don't involve any sensory imagery; I didn't and couldn't visualize a five-dimensional space. Such imaginings have assignments without sensory imagery.

Gregory believes that the imagining of $\mathrm{p}$ can be a rational guide to the belief that $\mathrm{p}$ is possible only when the imagining of $\mathrm{p}$ makes $\mathrm{p}$ appear possible. Non-imagistic imaginings, according to him, do not make anything appear possible. Therefore, non-imagistic imaginings do not even provide defeasible prima facie justification for possibilities. They have no modal epistemological value, unlike imagistic imaginings, which offer prima facie justification for possibilities by making things appear possible.

The question is, why does Gregory think that the non-imagistic imagining that $\mathrm{p}$ does not make $p$ appear possible? In his own words:

Reconsider, first, our [A]-imaginings [i.e. sensory imaginings]. If we were to accept that we cannot have sensations of the type specified in [A], we would view our [A]-imaginings as having misinformed us about our sensory capacities; in that respect, our imaginations would have generated illusions. But if we were to accept that universes can only have finitely many stars, we wouldn't similarly regard our [B]-imaginings [i.e. non-imagistic imaginings] as misinforming us about what's possible — our [B]-imaginings wouldn't themselves have had an illusory character. (2010: 329)

Gregory's argument seems to be that, if non-sensory imagining of $p$ makes $p$ appear possible, then we would find the non-sensory imagining illusory and misleading if $\mathrm{p}$ turns out to be impos-

\footnotetext{
${ }^{4}$ I would like to thank Ross Cameron for pointing me to Gregory's work.

5 Talk of 'labels' and 'assignments' is Kung's (2010) terminology, not Gregory's. I borrow Kung's terminology here because his framework for describing the different components in an imagining is developed in more detail.
} 
sible. However, Gregory thinks that we would not find our non-sensory imagining of p misinforming even if it turns out that $\mathrm{p}$ is not possible. Therefore, he concludes that non-sensory imaginings do not make things appear possible in the first place.

It seems pretty clear to me that, if I conceive of $p$ in a non-imagistic way but it turns out that $\mathrm{p}$ is not possible, I would consider my non-imagistic conceiving misleading. Before learning about Russell's paradox, I found a set of all the things that do not contain themselves as member conceivable. And that non-imagistic conceiving led me to think that a set of all the things that do not contain themselves as a member is possible. Once I learned about the paradox, I realized that my original conceiving was misleading, indicating that the conceiving did make the set seem possible to me. I was misled by my imagining. Thus, Gregory's argument against non-sensory imaginings is based on a very questionable premise, one that is not evident enough to be the basis of a compelling argument for thinking that non-imagistic conceivings don't make things appear possible.

Gregory goes on to say:

In particular, our imaginative imposition of non-imagistic constraints is like mere supposition and mere labelling in the following respect: our having imposed the constraints doesn't generally make their satisfaction appear possible, no more than mere suppositions and mere labellings typically produce appearances of possibility. In that sense, nothing generally 'follows from' a nonimagistic imagining concerning the possibility of its objects. (2010: 330)

This remark should not be read as an attempt to argue that, first, our non-imagistic imaginings are like suppositions, and second, our suppositions do not make what is supposed appear possible, therefore our non-imagistic imaginings do not make the imagined appear possible too. The remark cannot be read this way because there is an important difference between our non-imagistic imaginings and our suppositions: There are things that we can suppose but cannot imagine (in a non-imagistic way).

We suppose things that are plainly contradictory for the sake of reductio all the time - or just for the sake of it. Plain contradictions are inconceivable. Say I grant that some impossibilities can be imagined. (See Kung 2010: 626, also footnote 8 below.) But not all impossibilities are plain contradictions: it is not contradictory that water is XYZ, even though it is necessarily false. I'm also ready to concede that contradictions are also conceivable as long as they are well concealed. But plain contradictions like an apple's being both red and not red are inconceivable. ${ }^{6}$ If the range of non-imagistic imagination and the range of supposition are not the same, we cannot

\footnotetext{
${ }^{6}$ Geirsson (2005) makes a similar point about the inconceivability of contradiction. But I disagree with him when he says that this is due to the fact that we cannot understand contradiction. Non-sensory conceiving should not be identified with understanding. And that is exactly because we $d o$ understand contradiction; otherwise, we wouldn't be able to understand a reductio argument. (See also Yablo (1993) for a similar point.) Here I am not arguing that plain contradiction is inconceivable; I am stating as an introspective fact about our propositional attitudes that I cannot conceive of contradictions.
} 
argue that non-imagistic imagination does not make things appear possible simply because supposition doesn't. ${ }^{7}$

More importantly, even Gregory acknowledges the difference:

The range of things which we are capable of supposing outruns the range of things which we are typically happy to regard as imaginable. For instance, we can suppose that explicit contradictions hold, but more people deny being able to imagine explicit contradictions. I have no idea why this discrepancy exists. (2010: 330, footnote 26)

So he admits that 'more people' are inclined to draw a distinction between supposing and imagining when it comes to explicit contradiction. That alone should make it dialectically problematic for one to argue that imaginings have no modal epistemological value simply because supposings don't. Such a move is questionable even if Gregory himself appears to have reservations about the discrepancy. After all, although people's self-reports about their mental states are fallible, they should be taken seriously. As long as Gregory does not give us a compelling reason to think that the majority are wrong about their own mental states in this regard, such self-reports should be taken at face value.

It is due to this discrepancy that Gregory needs to qualify the alleged similarity between our non-imagistic imaginings and our suppositions in the follow way: they are similar in the sense that they both do not make things appear possible. But, of course, if this is the way to spell out the intended similarity between our non-imagistic imaginings and our suppositions, we cannot rely on this similarity to argue that our non-imagistic imaginings do not generate the appearance of possibilities without begging the question.

The comparison with supposition shouldn't be read as an argument for skepticism against the justificatory value of non-imagistic imaginings. However, the fact that Gregory made that comparison in the first place gives us some hint about what exactly about the non-imagistic imaginings that inspires his suspicion that non-imagistic imaginings do not produce appearances of possibilities. It seems to me that the suspicion stems from the fact that, just like our power of forming supposition, our power of non-imagistic imagination is very liberal.

But this suspicion alone doesn't yet give us any compelling argument against appealing to non-imagistic imagination in our modal epistemology. The world could have been wildly different in numerous ways. If so, it's simply to be expected that, whatever capacity we can rely on to form a broad range of justified modal beliefs, that capacity is meant to be very liberal in granting

7 This is a reason to reject Currie \& Ravenscroft's (2002) view that non-sensory imagination/conceiving just is assuming (9). Similarly, Ichikawa \& Jarvis (2012) defend the view that non-sensory imagination just is some kind of supposing. But to avoid the kind of worry I raise here, they add that imagining that $p$ is supposing that $\mathrm{p}$ and finding no absurdity among p's immediate logical consequences. Adding the bit about no immediate logical absurdity is to avoid the imagining of the plain inconsistencies, which can be supposed as I pointed out. Technically, that extra bit can do the job. I have my concerns about Ichikawa \& Jarvis' approach, but addressing that is beyond the scope of this paper. Instead, I will just point out that, by adding that extra restriction on imagining, we are already admitting that imagining is more restrictive than supposing and hence one can't directly infer from what supposing can't justify to what imagining can't justify. (That is not what Ichikawa \& Jarvis does.) 
possibilities. Thus, simply pointing out that our non-imagistic imagination is very liberal doesn't say much against non-imagistic imagination's modal epistemological value.

To build a case against non-imagistic imaginings, much more has to be said about the liberal nature of those imaginings - not just that they are very liberal, but in what sense they are too liberal to have modal epistemological value. Gregory fails to offer any explanation as to why they are too liberal to make things appear possible. Without such an explanation, we do not yet have a compelling skeptical argument. This is where Kung has more to offer.

\section{Kung's Argument}

Kung's (2010) project is meant to be anti-skeptical. It is an attempt to resist radical skepticism about the modal epistemological value of imaginings. He observes that we can imagine impossibilities. He takes this to show that our imagination is an unreliable source of modal justification. We should not rely on imagination for modal justification unless we can show that (i) there is a sub-category of imaginings that do not provide modal justification for a principled reason and that (ii) all imaginings of impossibilities happen to fall neatly into this sub-category. By showing that, the imaginings of impossibilities would be 'quarantined' and prevented from threatening our appeal to other imaginings for modal justification. And Kung argues that nonsensory imaginings is the sub-category we need. (Kung's 'non-sensory imagining' is, roughly speaking, Gregory's 'non-imagistic imagining.')

Kung's anti-skeptical project is ill-motivated. Let us grant him that we can imagine impossibilities. (Otherwise, there is no issue about reliability to begin with.) ${ }^{8}$ But still, that alone doesn't show that imaginings are unreliable. For most advocates of conceivability-based modal epistemology, imaginings are meant to be a fallible guide to possibilities. So surely there are impossibilities that we can imagine. That does not mean our imagination is unreliable. It would not help to say that we can imagine impossibilities 'very easily' (Kung 2010: 633), for 'reliability' is a statistical notion, not a notion about how much psychological effort we have to put into imagining impossibilities. Since I can imagine a vast number of things that are unquestionably possible, it remains far from obvious that imaginings are indeed unreliable.

Setting the concern about Kung's anti-skeptical project aside, what we want to focus on is the skeptical aspect of his work: the part where he says that there is independent reason for think-

\footnotetext{
${ }^{8}$ Here I am just playing along with Kung's claim that we can imagine impossibilities. Kripke famously disagrees. He thinks that cases where we seem to conceive of something impossible are deceptive (e.g., we are not really conceiving that Hesperus is not identical to Phosphorus when we appear to do so). Although Kripke is very influential on the contemporary discussions of modality, I do not think this particular view is widely accepted. Although it is plausible to say that we are occasionally mistaken when we think we are conceiving of something impossible, it is not widely accepted that this is always the case. For example, one of the things that Chalmers's popular two-dimensional framework does is to pull apart two different layers/dimensions of mental content (primary vs. secondary intension). By doing so it allows conceivability (possibility along the primary intension) and metaphysical possibility (possibility along the secondary intension) to come apart. It is conceivable that water is not $\mathrm{H}_{2} \mathrm{O}$ in Chalmers's framework. See also Kung (2016: footnote 11) and Ichikawa \& Jarvis (2012) about the Kripkean view that we cannot imagine the impossible. Furthermore, since I am granting Kung the point that we can imagine impossibility, I set aside Byrne's (2007) view. This view holds that to say that $\mathrm{p}$ is conceivable just is to say that $\mathrm{p}$ is possible, not only because the two can come apart, but also because, presumably, I can coherently and meaningfully say that they come apart.
} 
ing that non-sensory imagining is not a source for modal justification. As long as that independent reason stands, we have an argument against Imaginative Conservatism.

Kung argues that there are three restrictions upon non-sensory imagination: (i) certainty about otherwise, (ii) incoherence, and (iii) imaginative resistance. For a statement $\mathrm{S}$, we would fail to conceive that $S$ when we're absolutely certain that not-S, leaving us no room for imagination. And we would also fail to imagine that $S$ when imagining that $S$ is to imagine something incoherent. Finally, imagining that $\mathrm{S}$ is sometimes difficult when we're, for whatever reason, unwilling to find $\mathrm{S}$ conceivable and hence experience what philosophers sometimes call imaginative resistance. So, I can conceive that $\mathrm{S}$ as long as (i) I'm not certain that not-S, (ii) $\mathrm{S}$ is coherent with what I believe, and (iii) I'm willing to conceive that S (2010: 628-633).

But, according to Kung, the fulfillment of these three conditions doesn't seem to relate us to modal truths. For example, on condition (i), Kung says:

Believability just is lack of certainty. [...] It would be very odd if our non-certainty counted as evidence of P's possibility. [...] [T]o be non-certain is to fall short of the very best epistemic position one can be in [...]. We need positive evidence for our claims of possibility, but assignments don't provide it; they merely reflect our less-than-ideal epistemic position. (ibid: 634 )

Kung says it would be 'very odd' for believability (i.e., non-certainty of some sort, according to Kung) to provide modal evidence. But why is it very odd? If we can't tell what's so odd about it, we can't just assert that assignments don't provide evidence for possibility. I take it that this is the supposed oddity: Non-certainty is about our less-than-ideal epistemic position and that doesn't seem to be related to any modal truths. Thus, this constraint on assignments has no modal epistemological value. And something similar can be said about all three constraints: 'What this means is that none of the three constraints on imagining - certainty, conceptual, or conative - have any epistemic features to support assignments as evidence for possibility' (ibid: 636).

The constraints on non-imagistic imagination are not related to truths about possibility. That's why Kung thinks that, if non-sensory imagination is a faculty that works as long as the three conditions are met, it's too liberal a power to have anything valuable to say about modality. Hence, non-sensory imaginings don't provide even prima facie justification for modal beliefs and, in his own words, '[t]he reason is that stipulations and labels [i.e. the non-sensory assignments] are virtually unconstrained, and what minimal constraints there are have no modal epistemological value' (Ibid: 634; my highlighting).

Kung's argument isn't just based on the claim that imagination is very liberal. He explains why imagination is too liberal or insufficiently constrained by appealing to the fact that the only three constraints on non-sensory imagination don't seem to stand in any relevant relation with modal truths for the non-sensory imaginings to be a source of modal justification. That's why Kung's skeptical argument is immune to my concern about Gregory's attempt.

\section{A Dilemma for Moderate Skepticism}


Comparing Gregory's and Kung's arguments for Type-2 moderate skepticism shows the need for them to explain satisfactorily why non-sensory imaginings are not just very liberal, but too liberal for modal epistemology. Kung argues that the way to do so is to say that the restrictions on non-sensory imagination don't seem to relate our imaginings to modal truths. We have seen how he does this by proposing the three restrictions on non-imagistic imagining.

I am sure that many would have doubts about each of the three restrictions. ${ }^{9}$ I am not committed to the truth of these three restrictions. But I am not going to challenge them either. What I want to focus on is Kung's general skeptical strategy against the epistemological value of nonsensory imaginings. It is a strategy that helps fill in the gap that Gregory's attempt leaves open. The strategy begins by locating the constraints of non-sensory imaginings; then, by pointing out that those constraints do not relate our imaginings to modal truths, Kung appeals to the absence of a relation to modal truth as evidence against the epistemic relevance of those non-sensory imaginings.

The aforementioned skeptical strategy requires an assumption that is not yet explicit. Simply pointing out that X doesn't seem to be restricted in a way that is related to modal truths does not yet show that $\mathrm{X}$ is not a source of modal justification, unless we assume that being restricted in some way that is related to modal truths is necessary for something to be a source of modal justification. But that assumption poses a dilemma for the moderate skeptic. Why doesn't this concern about non-sensory conceivings challenge the epistemic value of our sensory conceivings too?

Kung says: 'Basic qualitative [i.e. sensory] contents are not unconstrained the way assigned [i.e. non-sensory] contents are, and so the foregoing concerns about assigned contents do not transfer to qualitative contents' (2010: 635). But the mere fact that the sensory conceivings are restricted by more than the three allegedly irrelevant limitations upon non-sensory conceivings doesn't make the sensory conceivings seem to be restricted in a more relevant way.

If the thought is that it'd be odd to say that the constraints on the non-sensory imaginings are evidence for modal beliefs in the sense that those constraints don't seem to be related to modal truths, it is not at all clear the constraints on sensory conceivings are any better. Do the constraints on the intrinsic qualitative features of my sensory imaginings really seem to be related to the wild modal reality, e.g., the possibility of a pink flying donkey? They don't seem any more related to modal truths than the constraints upon non-sensory imaginings. By parity of reasoning, shouldn't Kung be more radical in his skepticism about the epistemic value of our imaginings? What is so special about sensory imaginings that they can avoid the problem?

To explain the specialness of the sensory imaginings, Gregory writes:

Here is one way of incorporating appearance-based approaches to the imagination within a scheme for the justification of ascriptions of possibility. Begin with the idea that we are entitled to accept whatever is presented as being the case by some nondoxastic seeming [i.e. sensory appearance]. Next, take some occasion on which you imagine an $F$, with something's thereby appearing to you to be the case, where the accuracy of the foregoing

\footnotetext{
${ }^{9}$ Yablo, for example, would have a major qualm with Kung's claim that believability is the major restriction on non-sensory imagining.
} 
appearance seems very obviously to imply the possibility of $F$ s. Then (and assuming that you're entitled to assume that the previous implication holds) you are entitled to accept that $F$ s are possible. Hence your belief was in fact justified by your initial imagining. (2010: 327)

If I understand Gregory's reasoning correctly, the thought is that evidence for actuality is evidence for possibility. Sensory imageries are evidence for actuality; therefore, they are evidence for possibility. Sensory imaginings contain sensory imageries. That is why those imaginings are evidence for possibility. And this is a feature that non-sensory imaginings do not have.

This is an interesting suggestion, but I do not think it works. By simply visualizing a red tomato, do I thereby have any evidence at all that there is actually a red tomato? Of course not. Thus, sensory imageries alone clearly do not justify claims about actuality; only sensory imageries embedded in perceptions do. Since the sensory imageries in our sensory imaginings are not embedded in perceptions, they are not evidence for actuality. So, surely, Gregory is right that evidence for actuality is also evidence for possibility. But that gives us no reason at all to think that sensory imaginings provide evidence for possibilities while non-sensory imaginings do not.

About the specialness of sensory imaginings, Kung says something that sounds similar:

I think it is plausible that states with basic qualitative content provide evidence for possibility. The basic qualitative content of perceptual experience presents a way that space can consistently be filled around the perceiver. When my perceptual experience presents a red surface to my right and a black surface to my left, we theorists can say that, as far as the experience presents, a red surface on the right is consistent with a black surface on the left. That is one way that space could be filled. (2010: 637)

Kung appears to be making the same point as Gregory: the qualitative contents (i.e., the sensory imageries) provides modal justification in the case of perception, so it should provide modal justification in sensory imaginings as well. That is why sensory imaginings are special. However, there is a crucial difference. Kung explicitly denies in a footnote that perception of $p$ justifies the possibility of $p$ via (i) justifying the actuality of $p$ plus (ii) the principle that actuality entails possibility:

One way to block the intuition that qualitative contents provide evidence for possibility is to hold that we infer possibility from actuality; perceptual experiences furnish no evidence for possibility except insofar as can be inferred from actuality. (I.e., experience presents space in way $\mathrm{W}$; the world is such that $\mathrm{W}$; whatever is actual is possible; therefore, way $\mathrm{W}$ presents space consistently.)

It strikes me that this confuses conceptual priority with epistemic priority. It may very well be that the concept of truth is more fundamental than the concept of possibility, and possessing the former concept is a prerequisite for acquiring the latter. But it does not follow that perceptual experiences cannot be a basic source of evidence for possibility. I think that is the more plausible view; and in fact I am inclined toward an even stronger 
line of reasoning: perceptual experience must provide evidence for possibility for it to provide evidence of actuality. (ibid: 638 footnote 22 )

Kung thinks that sensory qualities provide modal justification directly - there is no inference from actuality to possibility involved. That makes his response immune to my objection to Gergory's response.

But Kung's assertion that sensory qualities provide modal justification directly is very controversial. And he offers no motivation, let alone justification, for the assertion. In particular, his response is not dialectically helpful in the current context, where modal skepticism is exactly the issue at stake. We want to know why having sensory imageries makes sensory imaginings modal epistemologically special, such that they can circumvent the skeptical concern for non-sensory imaginings. Kung's answer is tantamount to just asserting that sensory imaginings are epistemically special. ${ }^{10}$

Kung is not unaware of the dialectical shortcoming of his assertion of our sensory imaginings' specialness:

Although I think these considerations about basic qualitative content are plausible [i.e. that the qualitative content of sensory imaginings are not only bound by the three restrictions upon no-sensory imaginings], I realize they may not convince a hardened modal skeptic. I am engaged in what Pryor calls (with respect to external world skepticism) a 'modest anti-skeptical project' (Pryor, 2000, p. 517) for modal epistemology: showing that by starting with premises that we find plausible - rather than only those the skeptic will grant us - we can defend an imagination-based modal epistemology. (2010: 638)

Pryor et al. think that anti-skepticism doesn't have to be exclusively based on premises acceptable from a skeptic's point of view. Pryor thinks that, as long as one perceives that $p$, one has prima facie justification for believing that $\mathrm{p}$. We don't need any underlying theory to justify perception's prima facie justificatory value. This allows Pryor to rationally resist falling into skepticism, even if that reasoning cannot convince a skeptic in a non-question-begging manner. ${ }^{11}$

Kung tries to say something similar about the sensory conceivings. There's no non-questionbegging argument against the radical skeptics who dismiss the epistemic relevance of any conceiving (sensory or not). But it can be a starting point for non-skeptics to think that sensory conceivings provide prima facie modal justification. And such a starting point would allow philoso-

${ }^{10}$ On a similar note, Gregory writes: 'Those are good questions and I've not got answers to them. [...] But the queries just raised don't undermine the claim that sensory imaginings produce appearances of possibility; they merely underscore how hard it is to provide a philosophically adequate description of what's going on when imaginings produce such appearances' (2010: 332). I find such kind of hand-waving remark dialectically problematic, particularly in a context where Gregory is raising an argument against the epistemic relevance of non-sensory imaginings.

${ }^{11}$ A similar approach in epistemology has been further developed to include not only perceptions, but seemings in general (whatever they are) by Huemer $(2001$; 2007) in the form of Phenomenal Conservatism. 
phers like Kung to rationally resist falling into radical skepticism. The underlying constraints on the sensory imaginings don't seem to relate to modal facts? That's alright. Sensory imagining is a source of foundational modal justification that makes things seem possible. As a source of modal justification, its justificatory power does not need to be further explained by its underlying constraints' relation to modal facts.

However, I believe a double standard is at work in the way Kung uses Pryor's approach to defend the epistemic relevance of sensory conceivings alone. If Pryor's dogmatist approach works for defending the epistemic relevance of sensory conceivings, nothing prevents one from saying the same thing about conceivability in general. The skeptical worry about the non-sensory conceivings is basically in the same spirit as the radical skeptical worry about the sensory conceivings.

The underlying constraints on our non-sensory imaginings don't seem to relate to modal facts? That's alright. Non-sensory imagining is also a source of foundational modal justification that makes things seem possible. As a source of modal justification, its justificatory power does not need to be further explained by its underlying constraints' relation to modal facts. It seems that there is no principled way in which Kung can allow the dogmatist approach to save the sensory imaginings from radical skepticism without allowing the same dogmatist approach to save the non-sensory imaginings from his own moderate skepticism.

It is certainly not logically inconsistent to treat the two kinds of imaginings differently. But his reason for holding the hybrid view puts him in a dialectically awkward position. As long as Kung doesn't want to be skeptical about sensory imaginations for the kind of reason he offers, the only fair thing to do is to accept that conceivings generally provide prima facie modal justification, i.e., to accept Imaginative Conservatism. ${ }^{12}$

\section{Radical Skeptics}

I have argued that the general strategy for defending Type-2 moderate skepticism puts the advocates of Type-2 moderate skepticism in a dilemma: either give up the moderately skeptical argument and accept Imaginative Conservatism, or stick to the spirit of their skeptical argument and abandon imagination completely. There is no principled way that Kung's argument would work against non-sensory imaginings without also working against sensory imaginings. There's no well-motivated middle ground. Since the Type-2 skeptics don't want to give up sensory imagination, they should accept Imaginative Conservatism.

That might be good enough to persuade some of the Type-2 skeptics to embrace Imaginative Conservatism. But can they opt to give up sensory imagination instead, and be radically skeptical about the role of conceivings in modal epistemology? In a sense, this is what Fiocco (2007) does. Fiocco denies the epistemic relevance of imagination completely, which he deems too liberal to be epistemically relevant at all. He argues that, if we think that we can have modal knowledge at

\footnotetext{
12 It is instructive to observe that it would not be helpful simply to point out that, with all the Kripkean necessary a posteriori truths around, it is easier to find non-sensory imaginings of impossibilities than to find sensory imaginings of impossibilities. The fact that it is easier does not mean it is too easy. Even if it is easier for non-sensory imaginings to get modal truths wrong, that would not explain why non-sensory imaginings do not provide modal justification at all.
} 
all, we have to follow Bealer (2002) in postulating a distinct faculty of modal intuition. ${ }^{13}$ I'll complete my defense by arguing that, when it comes down to a choice between Imaginative Conservatism and radicalizing the skeptical argument, there's an independent reason for picking Imaginative Conservatism instead of doubling down on the skeptical argument.

If Kung et al. want to stick to the spirit of the argument and be radical skeptics about the epistemic value of conceivability, the skeptical argument should be radicalized in the following way: [a] if imaginings (sensory or not) are not too liberal to be epistemically relevant, they should be restricted in a way that somehow relates us to truths about possibilities. [b] But they don't seem to be restricted in such a way. Thus, we have a reason to think that, generally, conceiving is too liberal to be epistemically relevant.

My response is this. [1] Appealing to conceivings to justify beliefs about possibility is our current epistemic practice. [2] We shouldn't give up our current epistemic practice unless there's strong reason to do so. ${ }^{14}$ [3] The radically skeptical argument requires a hidden assumption which is very controversial. [4] The controversial assumption makes the radically skeptical argument too weak to demand giving up our current epistemic practice. Thus, if we have to choose between Imaginative Conservatism and the radically skeptical argument, it's more reasonable to choose the former.

Let's examine the premises of my response. I think whatever one's considered modal epistemology turns out to be, premise [1] is prima facie plausible. When I am asked whether I could have been taller than I actually am, how do I proceed in answering the question? I try to conceive of myself as being taller. I can conceive of that. For that reason, I am justified in believing that I could have been taller. Appealing to imagination is one of the most natural reactions people have to questions about possibilities. ${ }^{15}$

${ }^{13}$ I say 'in a sense', because Fiocco doesn't make the distinction between sensory and non-sensory conceiving.

14 This is why I call my main thesis Imaginative Conservatism. It should be noted that Imaginative Conservatism is neutral with respect to Huemer's Phenomenal Conservatism, which says that seemings give us prima facie justification. Imaginative Conservatism remains neutral in the sense that it says nothing about seemings at all. As we have seen earlier, Gregory believes that if imaginings can offer modal justification at all this must be done via generating seemings of possibilities. And he believes that non-sensory imaginings do not generate modal seemings. In section 2, I granted Gregory the assumption and played along; I argued that Gregory has offered no good reason to think that non-sensory imaginings produce no modal seemings. So there is no reason for an advocate of Phenomenal Conservatism like Gregory to reject Imaginative Conservatism. But that does not mean I am committed to the claim that imaginings provide modal justification only if they generate modal seemings. A defender of Imaginative Conservatism has the option to reject Phenomenal Conservatism (perhaps by denying that there are such things as seemings). In fact, as the argument [1] - [4] shows, Imaginative Conservatism can be defended on the basis of being conservative about the standing epistemic practices, with no mentioning of seemings at all. I am grateful to an anonymous reviewer for pressing me to clarify the relation between my view and Phenomenal Conservatism.

15 It has been argued that to say that $p$ is conceivable just is to say that $p$ is possible and that, because of this, it is wrong to conclude that conceivability is evidence for possibility. But we must reject this argument provided that we, like Kung, accept that something impossible can be conceived. 
By 'current epistemic practice', I don't just mean epistemic habits that we happen to have, but epistemic habits that we generally find reasonable. Certainly we don't consider all of our immediate reactions reasonable; but for those that we find unreasonable, we'd feel the urge to retract our reactions once they were brought to our attention. (This is the case, for instance, with a lot of our implicitly sexist or racist biases or practices.) On the contrary, an appeal to conceiving for modal justification is not the kind of immediate reaction we would ordinarily feel the urge to retract even when brought to our full awareness. That is why [1] seems very plausible to me.

I take premise [2] for granted. We can view [2] as a kind of epistemic conservatism, which is defended in slightly different forms by, just to name a few, Quine (1953), Chisholm (1980), Kvanvig (1989), and McCain (2008). I find [2] rather intuitive and don't have much to add in its defense. But it'll take some work to justify [3] and [4].

\section{The Hidden Assumption and its Motivation}

Premise [3] says that there is a hidden assumption in the radically skeptical argument. Here it is:

[Truth Relating] If $X$ is the source of epistemic justification for our belief on a subject matter, X must be related to the truth on that subject matter in a way that does not have to be characterized in terms of epistemic justification.

The qualification 'in a way that does not have to be characterized in terms of epistemic justification' is needed to avoid trivializing the relation to truth the skeptics have in mind. Without this qualification, Kung's argument cannot go through, for defenders of Imaginative Conservativism can then say that the constraints upon our conceivings are related to modal truths because our conceivings provide justification for believing that certain modal claims are true. What skeptics like Kung are getting at is a relation to modal truths that explains justification, not one that is characterized in terms of justification.

A tacit endorsement of this necessary condition for epistemic justification is the only reason for one to accept the radically skeptical argument's premise [a], namely: as long as it doesn't seem that our conceivings are restricted in a way that relates appropriately to modal truths, we have good reason to think that our conceivings do not justify modal beliefs.

It is fine to say that a certain relation to truth is sufficient for epistemic justification. It is, however, a different thing to say that it is necessary. Given that we appeal to so many different things to justify our beliefs/theories (e.g., perception, testimony, parsimony, mathematical elegance, moral sentiments, etc.) and not all of them are obviously truth relating, a monopolizing claim like Truth Relating isn't self-evident and needs proper motivation if we want to use it to challenge a standing epistemic practice. Certainly one can have the theoretical aspiration to try to unify all kinds of epistemic justification with a necessary condition like Truth Relating (e.g., Kelly (2004) tries to justify appeal to parsimony in terms of its truth conduciveness), and rule out everything else as an illegitimate source of epistemic justification. But for the radically skeptical argument to demand the abandonment of one of our epistemic practices, one needs to explain 
why there must be such a unifying necessary condition for epistemic justification. That is, Truth Relating had better be well-motivated. ${ }^{16}$

How can Truth Relating be motivated, then? As far as I can tell, the only way to motivate it would be to claim that epistemic value is a kind of instrumental value in the following sense: epistemic justification is nothing but a means or an instrument for guiding us to truth by recommending that we accept certain beliefs. ${ }^{17}$ If we think that there can be some other goals for epistemic justification, we have no reason to rule out the possibility that there are sources of justification that do not relate to truth in the way that Truth Relating requires. For example, a descriptive metaphysician might think that part of the goal of metaphysics is to find a theory that is rational in the sense that accepting it, in addition to being psychologically realistic for us, enriches our lives. (See, e.g., Strawson 1962). Such a goal does not seem to be related to truth at all.

To see why Truth Relating is controversial and hence why [3] is true, we need to examine what this instrument-for-truth conception of epistemic justification implies by taking a little detour: We need to examine the concept of a good instrument.

\section{What Makes an Instrument Particularly Good?}

We can talk about the goodness of an instrument in two ways: either with respect to a type of job in a type of situation, or with respect to a job token in a situation token. For example, suppose a zombie is running towards me, and I am wondering whether my gun is a good instrument for killing the zombie. There are two different questions I might be asking myself.

First, I might be asking whether the gun I am holding is good for zombie killing (as a type of job) in a certain type of circumstance where a zombie is running. Let's call this a question about General Evaluation. But, secondly, I might be asking whether my gun is good for killing this particular zombie in this particular circumstance (not this or that type of circumstance, but this circumstance in particular). Let's call this a question about Particular Evaluation. General Evaluation and Particular Evaluation can come apart. A lullaby can be good generally for getting a baby to sleep on a typical night; but that same lullaby can nevertheless be an instrument that is not good particularly for getting this baby to get to sleep on this night. Both evaluations (one positive, one negative) can be true of the lullaby as an instrument at the same time.

We know how to carry out a General Evaluation; all we need is to see whether an instrument is statistically likely to generate the desired result for a job type in the targeted situation type. For that reason, it's quite clear an instrument can be good generally for a type of job in a type of situation even if that instrument doesn't work for a particular job in a particular case, as I have illustrated with the lullaby case. How about Particular Evaluation? How do we carry it out? Unlike

\footnotetext{
${ }^{16}$ Questions about this single-minded conception of epistemic rationality have, in recent years, been raised not only by those who challenge epistemic consequentialism (e.g. Berker 2013), but also by some virtue epistemologists (e.g., Montmarquet 1993), by philosophers defending the idea of pragmatic encroachment (e.g., Fantl \& McGrath 2009), and by feminist metaphysicians following Haslanger's ameliorative project $(2000 ; 2006)$. They all, in their own way, try to explore the idea that there are factors that can serve as reasons for theory choice that do not involve relating us to the relevant truths.
}

${ }^{17}$ I could be wrong and there might be other ways to motivate Truth Relating. I don't have an argument to show that this is the only way other than that this is the only promising way I can see. 
General Evaluation, I don't think that an instrument can be good particularly for this job in this situation if the instrument doesn't work for this particular job in this particular situation. That is, I endorse the following:

[Job Failed] If $\mathrm{x}$ fails in doing a particular job in a particular situation, $\mathrm{x}$ is not a good instrument particularly for that particular job in that particular situation.

Whereas failing to do a particular job is not sufficient for an instrument to be evaluated as bad generally, failure is sufficient for the instrument to be evaluated as bad particularly. According to Job Failed, if I shoot this zombie in its head in this token situation and this zombie doesn't die, my gun is an instrument not good particularly for this token job in this token situation - it does not matter what exactly about this very zombie or this very situation that causes the failure. This is perfectly compatible with saying that the gun is still an instrument that is good generally for a zombie-killing job in that kind of situation. ${ }^{18}$

Job Failed is motivated by the way we judge the instruments we use in everyday life. For example, Job Failed explains why we are inclined to say, in the lullaby case, that - if the lullaby fails to put this baby to sleep tonight - the lullaby is not an instrument that is good for putting this baby to sleep on this particular night, even though the lullaby may still be generally good for putting babies to sleep at night. There is absolutely no point at all for insisting that the lullaby is good for putting this baby to sleep on this very night given that it does not work (whatever it is about this baby and/or this night that explains the failure).

The point generalizes to the Particular Evaluations of all instruments. Hence, actual failure is sufficient for a bad Particular Evaluation. When we talk about the goodness of an instrument, we need to be clear what kind of evaluation we care about.

\section{Good Epistemic Justification as a Good Instrument for Truth}

Back from the detour. Suppose I have a particular belief B in a particular situation S. I wonder whether B is well justified. For the sake of argument, let's assume that epistemic justification is an instrument for truth. Then, to ask whether B is well justified is to ask whether we have good instruments that guide us to truth by recommending B. Our discussion about instrument evaluation applies.

Given the distinction between the General Evaluation and Particular Evaluation of an instrument, and given that we are to view good epistemic justification as a good instrument of some sort, we should now ask ourselves: When we ask whether I have good epistemic justifica-

\footnotetext{
18 Note that saying that my gun is bad particularly for killing this very zombie $\mathrm{Z}$ does not immediately imply that it is irrational for me to pick my gun to kill Z. For, in picking my gun to kill Z, I might not be in a position to know that my gun is particularly bad for killing Z. We need to separate the metaphysical issue from the epistemic issue. Job Failed is about the metaphysical issue of what constitutes the goodness of an instrument for a particular job in a particular situation. What is rational for one to do at a time, however, is partly an epistemic issue, depending partly on whether one knows at the time which instrument is really good. Sometimes, we have to act by betting on what is good generally and hope that it is also good particularly. But the mere fact that it is rational to bet on something to work does not make that thing actually a good instrument for the job.
} 
tion for B, are we really asking (i) whether I have instruments that are good generally for targeting truth by recommending a certain type of belief in a certain type of situation, or are we really asking (ii) whether I have any instrument that is good for targeting truth by recommending this token belief B in this token situation, right here and right now?

Here is a simple argument for (ii). When we are wondering whether my belief B is justified, our concern is primarily about the truth of the following statement:

[a] I have justification for the belief B in this very situation S.

We would be disappointed as long as [a] is false. Since we are assuming that justification just is an instrument for targeting truth, we should be allowed to substitute 'have justification' with 'have a good truth targeting instrument for': 19

[a'] I have a good truth targeting instrument for the belief B in this very situation $\mathrm{S}$.

And what we said about [a] should apply to [a']. So, when we inquire about the justificatory status of my belief $\mathrm{B}$, our primary concern is the truth of [a] and hence [a'].

Note that to say [a'] is our primary concern is just to say that having a good truth-targeting instrument for this particular belief in this particular situation is our primary concern. And that is tantamount to saying that Particular Evaluation is our primary concern when we inquire about the justificatory statuses of our beliefs - assuming that justification is to be understood as a truth targeting instrument. Our interest in General Evaluation, on the contrary, is secondary or derivative.

It is noteworthy that this conclusion is in fact in line with how we think about ordinary instruments. When I want to put a nail through the wall of my office, I pick a hammer. By picking the hammer, my primary concern is that that hammer can put the very nail I am holding into that particular wall in my office. Surely I also care whether a hammer is generally a good instrument for putting nails in walls. But I care about that only insofar as the general goodness of a hammer is a hint of the fact that this hammer can put this nail through this wall.

As I have argued in our detour, Particular Evaluations of instruments are governed by the principle Job Failed. According to Job Failed, an epistemic justification for B is bad if it fails its particular job, namely, fails in guiding us to the truth by recommending $B$. That happens when $B$ is false. As a result, an epistemic justification for B is bad if B is false. Generalizing this reasoning beyond the belief B, if Job Failed is true, then the assumption that epistemic justification is nothing but a truth targeting instrument implies that an epistemic justification is no good if the particular belief that that justification purports to support is false (i.e., if it failed at its job). Note that to have bad justification is to have no justification at all. So our assumption has led to the claim that false beliefs aren't justified at all. Surprisingly, this is infallibilism about epistemic

\footnotetext{
19 If one resists the substitution, one basically resists the truth-targeting instrument conception of epistemic justification.
} 
justification. ${ }^{20}$ So although Truth Relating itself does not imply infallibilism, to accept Truth Relating not as brute but as a motivated principle, we have to accept a conception of epistemic justification that implies infallibilism.

Of course most people who accept Truth Relating (e.g., reliabilists) want to say that justified false beliefs are possible (after all, the plausibility of fallibilism is exactly the force of my argument). For example, when I hallucinate an apple on the table, most people want to say that, all else being equal, I am thereby justified in believing that there is an apple on the table even though there is no apple on the table. They can say so. I am not denying that it is consistent for them to assert both Truth Relating and fallibilism. But the consistency of these claims is beside the point.

What I have argued is that, although the plausibility of fallibilism may urge us to deny that Particular Evaluation is the standard for good justification, the truth-targeting-instrument conception of epistemic justification tacitly requires us to accept that Particular Evaluation is the primary concern for justification. If the skeptics do not want Truth Relating to be an unmotivated brute assertion, their only option (that I can see) is to motivate it with the truth-targeting-instrument conception of epistemic justification. And it is this conception of epistemic justification that, whether they like it or not, entails infallibilism.

Let's take stock. The radicalized skeptical argument works only if we accept the hidden assumption Truth Relating, which expresses a necessary condition for epistemic justification. And the skeptics either have to accept Truth Relating as brute, or offer some motivation for Truth Relating. Since not all the things we rely on as sources of justification obviously relate to truth (e.g., parsimony), it is controversial whether we should accept Truth Relating as brute. This is not a reason to reject Truth Relating, per se. There is nothing philosophically wrong in itself in accepting something controversial as brute. The problem arises, however, when we have to choose between accepting that as brute or sticking to our standing epistemic practice, and we cannot have both. To motivate Truth Relating, however, we need to accept the conception of epistemic justification that it is nothing but an instrument for guiding us to truth by recommending beliefs to us. By arguing for a principle about instrument evaluation, I have shown that the truth targeting instrument conception of epistemic justification turns out to imply infallibilism, ${ }^{21}$ which is, to say

\footnotetext{
${ }^{20}$ See Maitzen (1995) and Pollock (2004) for an argument in a similar spirit. This kind of argument is, as Maitzen points out, analogous to the argument against rule utilitarianism that it either turns into some form of rule worshipping or collapses into act utilitarianism. My argument, however, does not purport to challenge externalism as, e.g., Pollock (2004) does. I only question the motivation for accepting TruthRelating as a necessary condition for epistemic justification; it may still be reasonable to consider certain externalist relations to truth to be sufficient conditions for epistemic justification and, hence, externalism could still be well motivated.

${ }^{21}$ As Maitzen (1995) points out, this observation (mis-)leads some philosophers to think that all it takes to have knowledge is to have true beliefs - justification is redundant. Going on a slightly different route, Steglich-Petersen (2009) defends the truth-aiming conception of epistemic justification by embracing infallibilism (see also, Littlejohn (2012) who argues that when a belief is false the best we have is an epistemic excuse from epistemic blame, not justification; and the intuition against infallibilism is based on confusing excuse and justification). It is also interesting to note that, defending infallibilism of perceptual justification, instead of eschewing justification, McDowell (2011) is led to think that all it takes to have perceptual knowledge is justified belief — truth is redundant.
} 
the least, extremely controversial. So, accepting Truth Relating is a controversial move no matter what; and that's why premises [3] and [4] are true. Since a crucial premise of the radically skeptical argument needs but lacks proper motivation, it's more reasonable to choose Imaginative Conservatism instead of doubling down on the skeptical argument to its radical end.

\section{An Objection from Naturalism?}

My response to the radical skeptics in section 6 - 8 has a significance for conceivabilitybased modal epistemology that goes beyond simply urging the moderate skeptics to resist the temptation to go radical. It also serves as a principled answer to what Yablo calls 'the objection from naturalism' against conceivability-based modal epistemology (1993: 3-4). According to the objection, appealing to conceivings cannot provide modal justification because conceivings are causally isolated from the relevant modal facts. ${ }^{22}$

Instead of answering the objection head on, Yablo simply responds by gesturing at our mathematical knowledge - which is supposed to have a subject matter to which we have epistemic access despite our being causally isolated from it. But such a gesture is dialectically weak. After all, it is not as if people generally think that such an objection does not apply to mathematical knowledge. Quite the contrary, something similar to the objection from naturalism manifests itself as the famous Integration Challenge in the context of mathematical knowledge (Benaceraff 1973).

Note that the objection assumes that, if conceivings are epistemologically relevant, there must be a causal relation between our conceivings and the modal facts. Let's call this the Naturalistic Assumption.

If Truth Relating requires motivation, so does the Naturalistic Assumption. That is because the Naturalistic Assumption is in fact a restricted version of Truth Relating. Whereas Truth Relating says that some relation to modal truth is a necessary condition for modal justification, the Naturalistic Assumption says more specifically that a causal relation to modal truth is a necessary condition for modal justification. An analogy might help: If we need proper motivation for thinking that there are some unicorns in the universe, then we need proper motivation for thinking that there are some unicorns in USA specifically. If we aren't even motivated to accept the former, we most certainly aren't motivated to accept the latter. Therefore, if Truth Relating is not well motivated, neither is the Naturalistic Assumption.

Hence, my counterargument against the radically skeptical argument gives us the resources to resist the objection from naturalism as well: appealing to conceivings generally (sensory or not) for modal justification is part of our current epistemic practice, which should not be abandoned without good reason; the objection from naturalism is based on a premise that requires but lacks proper motivation unless we endorse the truth targeting instrument conception of epistemic justification, which implies the controversial infallibilism; therefore, the objection is not good enough to challenge the general appeal to conceivings for modal justification. The reasonable course to take is still to accept Imaginative Conservatism.

\section{References}

${ }^{22}$ I think this objection is similar in spirit to Peacocke's (2002) Integration Challenge about modality. 
Anscombe, G. E. M. 1974. “ "Whatever Has a Beginning of Existence Must Have a Cause”: Hume's Argument Exposed.' Analysis 34: 145-51.

Bealer, G. 2002. 'Modal Epistemology and the Rationalist Renaissnce.' In Gendler, T. S. \& Hawthorne, J. (eds.) (2002): 71-126.

Benaceraff, P. 1973. 'Mathematical Truth'. Journal of Philosophy 70(19): 661-679.

Berker, S. 2013. 'The Rejection of Epistemic Consequentialism.' Philosophical Issues 23: 363-387.

Byrne, A. 2007. 'Possibility and Imagination'. Philosophical Perspectives 21(1): 125-144.

Chalmers, D. 2002. 'Does Conceivability Entail Possibility?' in Gendler, T. S. \& Hawthorne, J. (eds.) (2002): 145-200.

Chan, T. (ed.) 2009. The Aim of Belief. OUP.

Chisholm, R. 1980. 'A Version of Foundationalism'. Midwest Studies in Philosophy 5(1): 543-564.

Cruz, J \& Pollock, J. 2004. 'The Chimerical Appeal of Epistemic Externalism.' In Schantz, R. (ed.) (2004):125-42.

Currie, G. \& Ravenscroft, I. 2002. Recreative Minds: Imagination in Philosophy and Psychology. OUP.

Fantl, J \& McGrath, M. 2009. Knowledge in an Uncertain World. OUP.

Fiocco, M. 2007. 'Conceivability, Imagination, and Modal Knowledge.' Philosophy and Phenomenological Research 74(2): 364-380.

Geirsson, H. 2005. 'Conceivability and Defeasible Modal Justification'. Philosophical Studies 122(3): 279-304.

Gregory, D. 2010. 'Conceivability and Apparent Possibility'. in Hale, B. \& Hoffmann, A. (eds.) (2010): 319-341.

Hartl, P. 2016. 'Modal Scepticism, Yablo-style Conceivability, and Analogical Reasoning'. Synthese 193: 269-291.

Haslanger, S. 2000. 'Gender and Race: (What) Are They? (What) Do We Want Them To Be?' Nous 34(1): 31-55.

—. 2006. 'What Good are Our Intuitions? Philosophical Analysis and Social Kinds.' Aristotelian Society Supplementary Volume 80(1): 89-118.

Hawke, P. 2011. 'Van Inwagen's Modal Skepticism'. Philosophical Studies 153(3): 351-364. Huemer, M. 2007. 'Compassionate Phenomenal Conservatism.' Philosophy and Phenomenological Research 74(1): 30-55.

—. 2001. Skepticism and the Veil of Perception. Rowman \& Littlefield Publishers. Ichikawa \& Jarvis 2012. 'Rational Imagination and Modal Knowledge.' Noûs 46(1): 127-158. Kung, P. 2016. 'You Really Do Imagine It: Against Error Theories of Imagination.' Noûs 50(1): 90-120.

—. 2014. 'You Really Do Imagine It: Against Error Theories of Imagination.' Noûs: doi: 10.1111/nous.12060.

—. 2010. 'Imagining as a Guide to Possibility.' Philosophy and Phenomenological Research 81(3): 620-663.

Kvanvig, J. 1989. 'Conservatism and its Virtues'. Synthese 79: 143-163.

Littlejohn, C. 2012. Justification and the Truth-Connection. Cambridge University Press. 
Maitzen, S. 1995. 'Our Errant Epistemic Aim.' Philosophy and Phenomenological Research 55(4): 869-876.

McCain, K. 2008. 'The Virtues of Epistemic Conservatism'. Synthese 164(2): 185-200.

McDowell, J. 2011. Perception as a Capacity for Knowledge. Marquette University Press.

McGinn,C. 2004. Mindsight: Image, Dream, Meaning. Harvard University Press.

Montmarquet, J. 1993. Epistemic Virtue and Doxastic Responsibility. Rowman \& Littlefield.

Peacocke, C. 2002. Being Known. OUP.

Pollock, J. 1999. Contemporary Theories of Knowledge (2nd ed.). Rowman \& Littlefield Publishers.

Pryor, J. 2000. 'The Skeptic and the Dogmatist.' Nous 34(4): 517-549.

Quine, W.V.O. 1953. 'Two Dogmas of Empiricism'. in From a Logical Point of View. Harvard University Press: 20-46.

Roca-Royes, S. 2011. 'Conceivability and De Re Modal Knowledge.' Noûs 45(1): 22-49.

Schantz, R. 2004 (ed.). The Externalist Challenge. De Gruyter.

Steglich-Petersen, A. 2009. 'Truth as the Aim of Epistemic Justification'. In Chan (2009) (ed.): 204-226.

Strawson, P. 1962. 'Freedom and Resentment'. Proceedings of the British Academy 48: 1-25. Van Inwagen, P. 1998. 'Modal epistemology.' Philosophical Studies 92(1): 67-84.

Williamson, T. 2007. The Philosophy of Philosophy. OUP.

Yablo, S. 1993. 'Is Conceivability a Guide to Possibility?' Philosophy and Phenomenological Research 53(1):1-42. 